\title{
Economic Scope Analysis on Online Media: The Case of Okezone.com
}

\author{
A M Putra ${ }^{1}$, K Jaya $^{2}$, D Andika ${ }^{3}$, M Rosit ${ }^{4}$ \\ 1,2,3 Universitas Mercu Buana, Jakarta, ${ }^{4}$ Universitas Pancasila-Jakarta \\ 1.afdal.makkuraga@mercubuana.ac.id, ${ }^{2}$ kusuma.jaya@mercubuana.ac.id, \\ ${ }^{3}$ dicky.andika@mercubuana.ac.id, ${ }^{4}$ muhammadrosit@univpancasila.ac.id
}

\begin{abstract}
Okezone is one of MNC Media's business units which engaged in online media news portals. This business unite first operated on March 1, 2007. Okezone.com has a variety of content from general news, politics, events, international, economy, lifestyle, celebrity, sports, auto, technology, food, travel, pilgrimage, Muslims, coffee shops and rubric. Okezone.com also collaborates with other MNC media business units such as TV Free to air, pay tv and e-commerce. The cooperation is in the form of distribution of Okezone content to promotion of Okezone activities posted both through the official website and social media of each unit. This research will focus more on three long tail forces, namely production democratization, distribution democratization and supply and demand democratization. These three forces are a set of new opportunities that arise in the long tail market. The methodology used in this research is a case study with data collection methods through interviews and direct observation. The results of this study explain that Okezone.com to run a business on digital media, has applied the concept of economic of scope, it is seen in hyperlinks of some content with fellow MNC groups.
\end{abstract}

Keyword: Media Economic, Economic of scope, Long tail

\section{INTRODUCTION}

In recent years the development of digital media business is growing fast, one of the causes is the growth of internet users in Indonesia. AC Nielson issued a press release explaining that internet growth penetration in Indonesia continues to increase, currently around one third of the population in big cities have had access to the internet in the last 3 months. The government's internet entry village program from the Ministry of Communication and Information also contributed greatly to the increase in internet users in Indonesia. [1]

In 2017, We Are Social, a social marketing agency, issued an annual report on data on the number of website, mobile and social media users from around the world. As many as 3,773 billion in total population worldwide, Indonesia is one of the countries that experienced a very fast growth of $51 \%$ and as many as 3,448 billion are active users (Wearesocial, 2017). [2]

Internet technology has one capability that is not possessed by other technologies, one of which is to erase the boundary between space and time, between one person and another, better known as the "Global Village", where the world can be analogous to a very large and vast village that can connecting all humans in the world. The concept of Global Village not only has an impact on the ease of communicating with other communities without having to think about 
space and time limits, but also many aspects such as the economy, social life, culture and so on [3]

The internet is growing among the public by offering something that conventional mass media cannot do. One of the impacts of the development of internet technology is the business model on mass media. This is in line with the opinion of the Minister of Communication and Information, Rudiantara at the DIGITALisMe Dig-In 2016 seminar in Jakarta, according to Rudiantara, digital in Indonesia is increasing, print and electronic media have moved to online media and social media.[4]

The concept of Economic of scale emphasizes more on the number of output volumes, so the average production costs get smaller so that the profits received by the company get bigger. While the economic of scope is where the situation of the Joint output of one company is greater than the output simply the company produces more than one type of goods sold. This as explained by Helge and Andreas Economic of scope exists when for all outputs y1 and y2 the cost of joint production is less than the cost of producing each output separately.[5]

The idea of a long tail (long tail) is based on several phenomena: (a) the tail of the variets that are available are far longer than we realize; (b) now within economic reach; (c) all of these celong, if combined, can constitute a significant market. None of the phenomena mentioned above can occur without cost reduction to reach niche market. At least three forces cause these costs to fall: democratization of means of production, democratization of means of distribution and the relationship between supply and demand.[6]

Chris Anderson in his book The Long Tail, Why the future of Business is Selling Less of More, explains the concept of long tail which is the culmination of a phenomenon of increasingly advanced technological developments that change the revolution in business activities both in finding, distributing, selling goods or services. Whereas the new economy sinks called the Long Tail, the economy of scope or abundance or describes abundance. The concept of long tail economic of scope, assumes that the higher the variety of products sold, the cheaper the production costs are helped by internet technology.

The book explains one example of the application of the long tail concept to the Rhapsody company, which is an online music company. The sales curve can be seen, the curve starts like the other demand curves, which are ranked based on popularity. Several hits are downloaded in large quantities at the head of the curve, and after that the curve drops sharply for less popular tracks. However, what's interesting is that the amount has never reached zero. For example, we check the 100,000th track, then we zoom in, 200,000, 300,000 and 400,000 tracks. No store can store this much. However, as far as is seen, the request still exists. Far from the curve, the track is still downloaded even if only four or five times a month, but the curve is still above zero. In statistics, such curves are called "long tail distributions," because the tails on the long curve are always compared to the head. From here was born the term The Long Tail, long tail.[7]

Growing internet technology opens new opportunities or celung in the context of marketing and sales flow called Niches. Niches is a stretch/chasm that has not been economically mapped to offer a large product, many types of products are available, just not visible and not easy to find. This concept creates "the new marketplace". With the limited effectiveness of traditional promotional media, the role of the internet media is greater in attracting buyers and driving sales. Niches main products or non-hits products have a very large number, on the other hand online trading via the internet can virtually store all goods or products. This has made a new breakthrough in the sale of non-hits products on the vast niche market. 
Most of the internet business entrepreneurs have expanded their business by applying the long tail concept. Like ebay (auctions), Yahoo! And Google (web search), Amazon (retail) and iTune Store (music) as well as smaller internet rulers such as Audble (audio books) and Netflix (video rentals).[8]

In Indonesia, the most visible developments in the digital media business (online news portal) such as Okezone, Kompas.com, detik.co.id, tribun.com etc. They are able to store as much information, news and other digital data as possible and offer it to public. The online news website above offers consumers everything from news that is becoming the center of attention/headlines/hotnews to news that is less attractive to readers. Interestingly, in this virtual business, even though Pareto's Okezone principles still apply, Anderson found that goods/products that included outside the $20 \%$ vital few were almost always sold/read at least once a month.

The object of research in this article is Okezone. In 2015, MNC Media Group's annual report stated that Okezone is one of the digital media owned by MNC Group which is the top 3 position as most read news portal by readers in Indonesia. Okezone is an embryo of online business owned by MNC Media Group, largest media company in Southeast Asia. This is also the main reason of why choosing MNC as the object of research (MNC Media, 2015). This research will explore more deeply how Okezone.com applies the concept of economic scope to the long tail economy model?

This research, emphasizes the application of economic scope proposed by Chris Anderson in his book The Long Tail, Why the future of Business is Selling Less of More and the concept of digital economy by Don Topscott in his book The Digital Economy: Promise and Peril in the age of Networked Intelligence. The collaboration between the two concepts is considered by the writer as a good composition because Don Topscott is one of the founder of the economy of digital media and the concept of Chris Anderson is considered as a fairly implementative concept in the current era.

This research is important to be carried out as the technological development in Indonesia is developing from year to year which impacts the growing number of online-based companies.

Preliminary study of the economy of scope of online mass media stated by Don Tapscoot. He explain the internet can transform computers and businesses in the world. Topscott predicts that in 2025, part of the human population, more than 4 billion people will use the internet, compared to 1996 with only 30 million users. He also predicted the internet would change human communication, both in the world of printing, telephone, television and even computers. This will have an impact on the economy and social life.[9]

Sooner or later the internet will destroy conventional businesses and produce something new. The impact of the digital economy is very clear as Tapscott said, never stop aligning IT and the business strategy, looking for ways to shape strategy. The future will not be a threat to the company if it can adapt quickly and become "Internet worked". Tapscott explained that later on technology would not only be a human tool but could also make a "money making machine". This journal not only discusses the smart machine, but also the smart community in combining a network.

The Tapscoot study was followed by David R. Burns of Southern Illinois University Carbondale, Depatment of Radio - Television and Digital Media Carbondale, IL, USA who wrote an article entitled The Economic Valuation of Digital Media Art published in Proceedings of the 21st International Symposium on Electronic Art 2015 David thinks that digital media economics is an alternative to the concept of classical media economics that is no longer effective in the midst of rapid technological development.[8] 
Classical economics assumes that, the more the demand the higher the price of the goods and the origin of an item is very important and of high value and cannot be reproduced. The exclusivity of goods is very important in understanding the classic model of economic value (CMEV). While understanding digital media artwork (DMA) considers all things can be reproduced. This uniqueness is the value of DMA, DMA can be accessed both in different platforms, times and places. Many people who use DMA to get a free or low price such as downloading music, ebooks, photos, software and so on.

Scoot McDonald writes a journal titled The Long Tail and It's implications for media audience measurement published in the Journal of Advertising Research, Vol. 48, No. 3, September 2008. This McDonald's explains the concept of the Long Tail, where Chris Anderson coined the term "The Long Tail" to describe business models that emerged as a result of revolutionary changes caused by digital technology. The internet only provides one prominent example: Because of the internet, many businesses are no longer limited to selling only their local articles, but can serve customers throughout a much larger area.[10]

Chris Anderson (2008)introduces the concept of long tail by explaining the business model to internet companies and online stores, or better known as e-commerce. Long tail is the study of the integration of the relationship between economic concepts, production costs, distribution costs, search costs and market performance to build the Long Tail in the online news business. [11]

New media is currently on its transformation way which is marked by the emergence of digital technology which has an impact on all media. As readers begin to move to digital media, many traditional media lose their readers, traditional media are challenged to be able to adapt to the phenomena that are happening now. Online news is now very popular in America as a daily news source. Six out of 10 Americans get online news from other media such as TV, newspapers, smart phones, tablets . As many as $65 \%$ of online readers don't have a favorite online news site, they read two or three online news sites to get news. [12]

The implementation of the long tail economy in online news portals with the three long tail power approach, first is democracy of means of production, democracy of means of distribution and connecting supply and demand. Online news is actually the most appropriate example where online news is a collection of niches by offering content that ranges from breaking news about local, national and international affairs to pages such as criminal news, celebrity gossip, crossword puzzles and horoscopes.

\section{RESEARCH METHOD}

This research uses a case study method [13] with a focus of study on the application of the economic scope at Okezone.com. The data collection technique used interviews with three key informants who were Okezone.com's manager and assistant manager. In addition to the interview the writer also made direct observations and compared some of the data with the results of the interview.

\section{RESULT AND DISCUSSION}

The process of analyzing the results of research carried out is to look for relationships between existing theories or concepts with the results of research obtained by researchers. Then the researchers conducted an analysis to determine the application of the long tail on Okezone. The analysis of this study reached the interview stage with the technical validity of triangulation data, namely with the main resource person Mr. Pigar, comparative resource person (secondary) 
Mr. Rori Hastomo and Mr. Guritno Himantoro. As explained above, this research focuses on 3 long tail forces, namely: Production Democratizations, Distribution Democratization and Supply and Demand Connection.

\subsection{Freedom of Production}

The personal computer is one of the devices that can make everyone a producer who initially can only be done by professionals. The same thing happened to the okezone company, where previously to make a story in a newspaper, there were a lot of tools and the manufacturing flow was quite long. Nowadays, with the advancement in technology, journalists or contributors simply use computers, laptops or smartphones to create news that can be easily posted on Okezone pages.

This democratization production which creates many variations of menus and content on Okezone portal, to date Okezone has a main menu consisting of: News, Finance, Lifestyle, Celebrity, Ball, Sport and Techno. Menus on okezone will be able to increase in accordance with editorial needs and special moments, for example okezone creates 2018 Election menu due to the election moment that will be held in the near future. On holiday season such as Eid alAdha when most of Indonesian Muslims go to Mecca for pilgrimage, Okezone also create special menu on their portal.

Although Okezone is engaged in digital business and also applies economic of scope, the concept of conventional business still becoming main consideration. Popular or trending products which is read by the majority of Indonesian people will always get more space compared to other groups, this is a way to attract Okezone Viewers.

Okezone also applies the concept of wikinomic, where the content is not only posted by journalists and contributors but also utilizes netizens or members of the Okezone website. This is commonly known as Prosumen. The intended producer, where producers can become consumers and consumers can become producers. Wikinomic is also facilitated by Okezone by making Rubric menus and coffee shops, menus where members of Okezone Websites are allowed to create news content, articles or personal opinions on several things, one of them is politics, hobbies, culture and so on.

Okezone website was not only displaying news, but there were also e-commerce menus such as flight ticket sales services, insurance, fashoin, and Okezone TV. Okeozone TV is a menu that allows okezone visitors to steaming 4 free TV to air and 4 pay TV.

The quantity of content posted on the Okezone website is delivered by Bpk. Pigar apparently also has no effect on the number of readers. For example, in 2016 Okezone once posted content as 1,000 pieces per day, but it did not affect the number of readers. In 2017 Okezone adjusts back the amount of content posted on Okezone website, not only considering the amount of content but also the quality of the content posted. The taste of the reader is also an important consideration for creating content, this can be seen by the average age of the reader and the type of work the website reader is reading.

\subsection{Freedom of Distribution}

If a computer can create new content, but only the internet can distribute that content to readers so will that be experienced by Okezone. The internet has become one of the most effective ways to distribute content and introduce Okezone to the public. Some ways that Okezone is used to distribute content and introduce Okezone to the public are: Okezone website, MNC Media website, MNC Media social media, internal email and through seaching engines.

Using the MNC Media corporate unit website to help distribute content, this can be seen on the RCTI, MNC TV, GTV, iNews websites, and all units under the MNC Media Group. 
In each MNC Media unit group at the bottom of the website a hyperlink will be included which if clicked, visitors will be directed to the Okezone website. The news listed on the website of each MNC Media group unit are headline or popular news that is read by the public and the news is presented in accordance with the updates contained on Okezone website.

The use of MNC Media social media units more often uses social media such as Twitter, Facebook and Instagram, these three platforms were chosen because of the large number of social media users in Indonesia who use these 3 social media. The three platforms are also considered the most interactive compared to other platforms, where there are comments, likes/love, live menus (Instagram and Facebook) and can create trending topics (Twitter). Some of these things are taken into consideration by optimizing these 3 social media to help distribute Okezone content.

Internal email is also used by Okezone, as a means of distributing content and promotions, dissemination via internal email MNC media is sent by HR holding to all MNC Media employees. Email content that is sent more often contains okezone headlines that are hits, promos, special events and other activities. The following is an example of an internal email sent by HR holding for Okezone activities.

Of all ways done by Okezone through websites, social media to internal e-mail, it turns out that the distribution of content through search engines is the most effective and widely used by many Okezone readers. This is also consistent with the results of interviews with Mr. Pigar and data from Alexa.

\subsection{Request and Supply}

Technological developments can link demand with supply and introduce readers to news ranging from popular to less popular. In supply and demand connections researchers see two things outlined first: readers with Okezone content and second advertisers with Okezone.

In economics, search costs refer to whatever is blocking the way when you want to find what you want. Some costs are not in the form of money, such as time being wasted, inconvenience, wrong purchase, and confusion.

This also applies to Okezone, advances in technology makes it easy for readers to find the news content they want, this can be done with a variety of searches ranging from directly from Okezone websites, wisdom-of-crowd typical of Google, links on social media, links on website which includes Okezone links, reader comments and so on.

Similarly, the relationship between advertisers and Okezone, where the content contained on Okezone website is not only based on the direction of the Chief Editor but can also be made based on requests from readers and advertisers. content ordered/advertisers from advertisers will be marked with adv (tutorial) with the intention that the content in the post is not news written by Okezone but paid content. The advertisement process is also quite simple where there is an ad info menu on the okezone website, advertisers will easily find information about costs, procedures and so on about advertising. advertisement will also be far more effective with many menu options to choose from in the menu where the ad will be posted, resumes of the number of people who clicked, shared, commented and only looked at it will appear as an advertisement report [14]

The application of the Long Tail concept to online news portals, especially in Indonesia, actually needs additional adjustments or strategies to become a top news portal. Okezone has applied the concept of long tail, both in content production, distribution to the demand and supply aspects, both those that are run alone or that involve other business units.

Although engaged in digital media, the concept of conventional business also remains implemented in Okezone business strategies. Companies engaged in the online news portal, 
engagement is very important compared to the number of news published on websites or other publication media. An additional strategy is needed to perfect the long tail concept, which can adapt readers in Indonesia. The time difference which is divided into 3 regions (Estern Indonesia Time/WIT, Central Indonesia Time/WITA, Western Indonesia Time/WIB), Indonesian Geography, reading culture and so on can be considered in making okezone business strategies.

\section{CONCLUSIONS}

Okezone.com applies economic of scope, where the joint output of one company is greater than output, the company simply produces more than one type of goods sold. Okezone website not only displays news online/digital, but also works with other companies such as airline ticket purchase services, hotels (Mister Aladin), vehicle insurance services (MNC Insurance), online fashion (thefthing), TV okezone (tv channels free to air and pay tv) and video sharing services (Metube). Okezone is also integrated with, Sindonews.com and Inews.go.id.

The idea of the Long Tail also applied by Okezone where all contents posted on the website must be read by at least one reader. This can be seen from the attorney's index on the okezone.com website where on each menu you will see the most popular to the less popular news.

Although Okezone.com uses the concept of digital business where limited space and time should be no longer a problem, in reality Okezone.com is still applying the conventional business concept. Okezone.com still considering the posting time of the news article due to time difference, e.g. they will synch the posting time to the local time since there are two hour of difference between Jakarta and eastern Indonesia.

Content distribution on Okezone.com via word search engines such as Google turns out to be in second place after Okezone Website not through hyperlinks on the MNC Media business unit website or MNC Media social media business unit. The content on Okezone is very flexible, where the news to be posted adjusts to the conditions that occur at this time or if there are special moments that will adjust to those moments, such as Eid al-Fitr, Christmas and New Year. These special moments will get a special "place" on Okezone website.

\section{REFERENCES}

[1] M. Lubis, "Konsumen Indonesia Mulai Menyukai Belanja Online,” Jakarta, 2014.

[2] S. Kemp, "Digital in 2017: Global Overview," We Are Social and Hootsuite, 2017. [Online]. Available: https://www.wfanet.org/app/uploads/2017/06/We-Are-SocialDigital-2017.pdf\%0Ahttps://wearesocial.com/uk/blog/2017/01/digital-in-2017-globaloverview. [Accessed: 28-Mar-2017].

[3] M. McLuhan, Understanding media: extension of a man. McGraw-Hill, 1964.

[4] Sina-Pih, "Menkominfo harap marketer kreatif gunakan platform digital," 2016. [Online]. Available: https://www.kominfo.go.id/content/detail/7152/menkominfoharap-marketer-kreatif-gunakan-platform-digital/0/berita_satker. [Accessed: 26-Mar2016].

[5] A. Henten and H. Godoe, "Demand side economies of scope in bundled communication services," Info, vol. 12, no. 1, pp. 26-38, 2009.

[6] C. Anderson, The Long Tail: Why the future of Business is Selling Less of More. Hyperion Book.

[7] G. D. Booth, "A Long Tail in the Digital Age: Music Commerce and the Mobile Platform in India," Asian Music, vol. 48, no. 1, pp. 85-113, 2017. 
[8] D. R. Burns, "The Economic Valuation of Digital Media Art," 2001.

[9] D. Taspcoot, Digital Economic: Rethinking Promise and Peril in The Age of Network Intelegent. McGraw-Hill Education, 2014.

[10] S. McDonald, "The long tail and its implications for media audience measurement," $J$. Advert. Res., vol. 48, no. 3, pp. 313-319, 2008.

[11] C. Anderson, The Long Tail: Why the future of Business is Selling Less of More. Hachette Books, 2008.

[12] A. Mitchell, J. H. Holcomb, and R. Weisel, "State of the News Media 2016," WD info, 2016. [Online]. Available: http://www.journalism.org/2016/06/15/state-of-the-newsmedia-2016/\#. [Accessed: 10-Aug-2017].

[13] R. Yin, Case Study Research: Design and Method, Second Edition, ISBN: 0-8039-56622. Sage Publication, 1994.

[14] K. Saddhono, A. Hasibuan, and M. I. Bakhtiar, "Facebook as A Learning Media in TISOL (Teaching Indonesian to Speakers of Other Languages) Learning to Support The Independency of Foreign Students in Indonesia," in Journal of Physics: Conference Series, 2019, vol. 1254, no. 1, p. 12061. 